\title{
O Second Life como plataforma para micromundos físicos para o ensino de Física"
}

\author{
Renato P. dos Santos \\ ULBRA/PPGECIM
}

e-mail: renato@fisica-interessante.com

\section{Resumo}

O objetivo deste trabalho é utilizar a idéia da hiperrealidade da Física do SL para demonstrar a viabilidade do ambiente do SL como suporte para micromundos físicos e simulações que permitam experimentação pedagogicamente efetiva com sucessivas leis físicas, diferentes das de Newton, num referencial histórico-psicogenético piagetiano, tal como proposto por Papert trinta anos atrás. Após delinear a concepção de Papert de um micromundo físico e as implicações de algumas características do ambiente SL para seu uso como suporte de micromundos, será apresentado um relato detalhado da construção de um exemplo concreto de micromundo físico, um 'canhão' que pode simular duas teorias físicas diferentes para o movimento de um projétil: a mecânica newtoniana bem como sua predecessora, a Teoria do Ímpeto de Buridan, à escolha do usuário.

Palavras-chaves: mundos virtuais, Second Life, micromundos físicos, Ensino de Física, simulações computacionais.

\begin{abstract}
The aim of this study is to pursue the idea of SL Physics hyper-reality to demonstrate the viability of the SL environment as a support for physical microworlds and simulations that provide pedagogically effective experimentation with successive physical laws different from Newton's ones, in a Piagetian historic-psychogenetical framework, as proposed by Papert thirty years ago. After outlining Papert's conception of physical microworld and the implications of a few specific features of the SL environment to its use as a support for microworlds, it will be presented a detailed account of the construction of a concrete example of physical microworld, a 'cannon' that can simulate two different physical theories for the projectile motion: the Newtonian mechanics as well as its predecessor, Buridan's Theory of Impetus, at user's choice.
\end{abstract}

Keywords: virtual worlds, Second Life, physics microworlds, Physics teaching, computer simulations

\section{Introdução}

Graças à crescente popularidade de jogos maciçamente multiusuários, como o bem conhecido World of Warcraft ${ }^{\mathrm{TM}}$, mais e mais pessoas estão experimentando com mundos virtuais 3D imersivos, com grande verossimilhança física com o mundo real, para simular sistemas, visando reconstrução histórica, planejamento urbano, ensaios em engenharia, treinamentos médicos, militares e de vendas e visualizações científicas, dentre outras finalidades (Lopes, 2009). Era, portanto, de se esperar que esses mundos virtuais começassem a forçar sua entrada na sala de aula, tal como fizeram e fazem tantas outras tecnologias, tais como os projetores de slides, a televisão, as calculadoras, os notebooks, os blogs, os RPGs e os iPads, com maior ou menor sucesso (Medeiros, 2008).

Este trabalho foi apoiado pelo CNPq, Edital Universal/2008, Proc. $n^{\circ} 481787 / 2008-9$. 
Como explicado adiante em mais detalhe, micromundos físicos são ambientes computacionais interativos de aprendizagem onde aprendizes podem brincar com uma variedade infinita de leis do movimento, incluindo leis que os próprios estudantes poderiam inventar por si mesmos (Papert, 1985).

O objetivo deste trabalho é utilizar a idéia da hiperrealidade da Física do SL e de seu potencial surreal, expresso por Santos (2008, 2009), para demonstrar a viabilidade do ambiente do SL como suporte para micromundos físicos e simulações que permitam experimentação pedagogicamente efetiva com sucessivas leis físicas, diferentes das de Newton, num referencial histórico-psicogenético piagetiano, tal como proposto por Papert trinta anos atrás. Após delinear a concepção de Papert de um micromundo físico, será apresentado um relato detalhado da construção de um exemplo concreto de micromundo físico, um 'canhão' que pode simular duas teorias físicas diferentes para o movimento de um projétil: a mecânica newtoniana e sua predecessora, a Teoria do Ímpeto de Buridan, à escolha do usuário.

\section{Micromundos físicos}

Já em 1980, Papert (1985) apontava que os estudantes quase não têm experiências diretas e físicas do movimento puramente newtoniano e, na sua ausência, as escolas são obrigadas a dar ao estudante representações altamente matemáticas, abstratas e indiretas de objetos newtonianos. O movimento newtoniano é aprendido por meio de manipulação de equações, em vez de manipulação dos próprios objetos. $\mathrm{O}$ aluno é obrigado a primeiro aprender a trabalhar com equações, antes de usá-las para modelar o mundo newtoniano. Além disso, os alunos são instados a usar as leis do movimento de Newton, sem saber exatamente o que uma é "lei de movimento" e se existem outras leis de movimento diferentes, além das de Newton. Repetindo um bem conhecido argumento, se alguém quer aprender a falar francês, ele deveria ir para a França; faria sentido, portanto, ir a um lugar onde os objetos obedecessem estritamente as Leis de Newton para aprender mecânica newtoniana.

Isso seria viável num "micromundo da física" (Papert, 1985), onde os estudantes poderiam progredir, numa sequencia de aprendizagem piagetiana, desde a histórica e psicologicamente importante física Aristotélica, passando pelas leis "corretas" de Newton, até a complexa mecânica de Einstein e até mesmo a leis de movimento que os próprios estudantes poderiam inventar por si mesmos, sem serem forçados a assimilar as teorias "corretas", antes de estarem prontos para entendê-las (idem, ibidem).

Encontram-se, hoje, vários simuladores de Física no ambiente Second Life, mas vale enfatizar que eles concentram-se em simular a Física Newtoniana. Várias experiências diferentes de ensino com micromundos podem ser encontradas na literatura desde as Dinatarts (tartarugas dinâmicas) de diSessa (Abelson e diSessa, 1981) aos nossos dias. No entanto, após trinta anos da proposta de Papert, embora muitos micromundos tenham sido construídos em diferentes plataformas, com exceção das primitivas 'Dinatarts' (tartarugas dinâmicas) de diSessa (Abelson e diSessa, 1981), não se tem conhecimento de implementações de micromundos que efetivamente disponibilizem essa experimentação com leis físicas diferentes das newtonianas, tal como concebida por Papert (1985). Além disso, como apontado por Vrellis et al (2010), enquanto as Ciências tem sido frequentemente relatadas como domínio preferencial para ambientes virtuais de aprendizagem, a maioria dos MUVEs tem sido utilizados como meros lugares de exploração e investigação com ênfase na interação do grupo e menos em aprender através da interação com o ambiente e modificação em uma abordagem construtivista. 
Uma realização interessante da sequencia de aprendizagem Piagetiana / Papertiana é os micromundos históricos de Masson (Masson e Legendre, 2008; Masson e Vazquez-Abad, 2006). Esses autores construíram um conjunto de três ambientes computacionais 2D de aprendizagem interativa, com o software Interactive Physics ${ }^{\mathrm{TM}}$, que respeitam, cada um, as concepções sobre o movimento de Aristóteles, a teoria de Buridan do ímpeto e as leis do movimento de Newton, respectivamente. Vale notar, no entanto, que, apesar da semelhança, este trabalho não foi baseado no de Masson já que só tomamos contato com ele quando este projeto já estava quase finalizado. Acreditamos, no entanto, que a 'sensação de presença', como uma entidade separada, que é uma característica chave dos ambientes virtuais 3D imersivos (MIKROPOULOS \& NATSIS, 2011), tornarão mais concretas nossas simulações de leis físicas alternativas e o aprendizado mais efetivo nos nossos micromundos físicos.

\section{Materiais e Métodos}

Neste trabalho, características específicas do ambiente SL relevantes para seu uso como suporte para micromundos físicos e simulações serão analisadas, após consulta às seguintes fontes, em adição à própria experiência do autor:

- LSL Wiki. (LSL Wiki, n. d.)

- Second Life Wiki. (Second Life Wiki, n.d.)

- Second Life Wikia. (Second Life Wikia, n.d.).

- Scripting Your World (Moore, Thome e Haigh, 2008)

Também serão discutidas algumas diferenças encontradas entre o SL e simuladores tradicionais como o Modellus, suas implicações para a simulação de Mecânica e algumas soluções para contornar as dificuldades daí advindas.

Após estas análises, será apresentado um relato detalhado da construção de um exemplo concreto de micromundo físico, um 'canhão' que pode simular a mecânica newtoniana bem como sua predecessora, a Teoria do Ímpeto de Buridan, à escolha do usuário, baseado na proposta nunca implementada de Papert (1985).

\section{Resultados e Discussões}

Mais do que apenas permitir a construção e manipulação de objetos, tais como chafarizes, armas ou veículos, como em outros ambientes virtuais, o SL oferece recursos para imbuir interatividade nos objetos, para que estes possam mover-se, ouvir, falar, mudar de cor, tamanho ou forma, e até 'comunicar-se' com outros objetos, através da sua linguagem de programação LSL (Linden Scripting Language) (LSL Portal. s.d.). Sua estrutura é baseada nas linguagens Java e $\mathrm{C}$ e disponibiliza quase quatrocentas funções, dentre as quais várias com interesse para o estudo da Física nesse ambiente. Por exemplo, llGetPos()e llGetVel() retornam vetores que correspondem, respectivamente, à posição e à velocidade do objeto na região; llGetOmega() retorna a velocidade angular do objeto e llSetForce() que aplica uma força ao objeto.

Entretanto, alguns pontos importantes devem ser levados em conta quando se pretende construir um simulador ou um micromundo físico no SL.

\subsubsection{Os objetos físicos são diferentes}

Por padrão, os objetos são criados no SL como não-físicos, isto é, com o atributo 'PHYSICAL' desativado. Um objeto pode ser tornado físico durante a edição marcandose a caixa "Physical" na janela de edição de objetos ou usando as funções llSetStatus ou IlSetPrimitiveParams da LSL. Objetos físicos podem, em princípio, ser afetados por 
'vento', 'gravidade' e colisões com outros objetos (SL Wiki, n.d., Non-Physical). A 'gravidade' no SL é realizada através de uma força constante aplicada a todos os objetos físicos com um valor dado por sua massa multiplicada por $9.8 \mathrm{~m} / \mathrm{s}^{2}$ no sentido $z$ negativo (LSL Wiki, n.d., gravity). Não foi, porém, implementada qualquer fricção com o ar ou com a água no SL (LSL Wiki, llWind) e, portanto, objetos físicos são, na prática, sujeitos apenas a 'gravidade' e colisões.

Certas funções da SLS, tais como llSetPos e llSetRot, chamadas funções cinemáticas (kinematic functions) (LSL Wiki, n.d., Dynamics), posicionam objetos não-físicos sem utilizar forças ou torques e, portanto, não atuam sobre objetos físicos. Outras funções, chamadas funções cinéticas (kinetic functions), tais como llSetForce e llSetTorque, operam somente sobre objetos físicos, já que geram forças e torques sobre eles, resultando em seu movimento. Há, também, funções que operam tanto em objetos físicos como não-físicos e ainda outras funções que não funcionam como esperado para objetos não físicos. Por exemplo, com a llRezObject, objetos não-físicos são materializados na posição indicada, mas estacionários, sem velocidade

\subsubsection{O SL não é um simulador usual}

Diferentemente de um simulador tradicional, como o Modellus (Teodoro, Vieira e Clérigo, 2000), faltam ao SL algumas funções básicas para prover condições iniciais de objetos, como simuladores usuais têm. Não há uma função como llSetVel para definir a velocidade inicial do objeto e a função llSetPos existente não atua sobre objetos físicos. Em geral, a única opção para colocar um objeto físico já existente em movimento são as funções llSetForce e llApplyImpulse, mas que não vão causar velocidade constante - ao contrário, o objeto irá começar a ganhar velocidade (acelerar), no primeiro caso, e a perder velocidade no segundo, devido ao amortecimento (mais corretamente, ao arraste). No entanto, é preciso admitir que também não temos tais recursos no mundo real - só podemos acelerar objetos (empurrando ou batendo) e retardá-los. Nesse sentido, a Física do SL é, novamente, mais real do que a Física da sala de aula.

\subsubsection{A Física do SL não é Newtoniana}

Vale a pena lembrar, também, que Santos (2008, 2009) já demonstrou anteriormente que a Física do SL não é nem uma virtualização da Física do 'mundo real' nem a da Física 'ideal' Galileana/Newtoniana. Em vez disso, concluiu que ela é hiper-real e que, apesar disso, proporciona recursos para construir simulações surreais, onde as leis físicas são diferentes ou alteráveis pelo estudante - micromundo físicos, portanto, resgatando a proposta nunca implementada de Papert (1985).

O resultado desta análise é que, portanto, é, definitivamente, possível construírem-se micromundos físicos no SL, ainda que sendo necessária alguma criatividade para contornar as mencionadas restrições e diferenças em comparação a um simulador 'clássico', conforme discutido no exemplo seguinte.

\subsection{Um exemplo concreto: construindo o canhão de Buridan}

Para investigar concretamente a viabilidade de dispositivos que não sigam apenas as leis da mecânica de Newton no SL, decidiu-se construir um'canhão', cujos projéteis, em vez de realizar o movimento parabólico usual, seguissem a bem conhecida Teoria do Impulso (impetus) de Buridan ([13--]), citado por Crombie (1957, p. 251), prevalecente na Idade Média. O conceito de impetus pode ser considerado um predecessor do conceito newtoniano de inércia. 
De acordo com ela,

"Um motor, ao colocar um corpo em movimento, infunde nele certo impetus, certo poder capaz de mover o corpo na direção em que o motor o colocou em movimento, seja para cima, para baixo, para o lado ou em círculo. [...] é por este impetus que a pedra é movida após o lançador ter deixado de movê-la (Buridan, 13--), citado por Crombie (1957, p. 251)”

Alberto da Saxônia usou a teoria de Buridan na sua explicação da trajetória do projétil incorporando a ideia de Hiparco de impetus composto e o princípio Aristotélico de que um corpo elementar só podia ter um movimento simples de cada vez (Crombie, 1957, pp. 254-5.). Ele afirmava que a trajetória do projétil era dividida em três períodos (Figura 1):

1. Estágio inicial: $O$ projétil se move em linha reta na direção em que o motor o colocou em movimento num movimento puramente violento. Durante este período, o impetus infuso aniquila ou supera o peso natural do projétil (trecho A-B na figura);

2. Estágio misto: A trajetória começa a se desviar para baixo da linha reta; por causa da resistência do ar e também por causa do peso do projétil o impulso do projétil é continuamente enfraquecido. Durante este período, o movimento é tanto violento quanto natural (trecho B-C na figura);

3. Estágio final: Movimento puramente natural para baixo depois que o peso do projeto e a resistência do ar superaram o ímpeto fornecido (trecho C-D na figura).

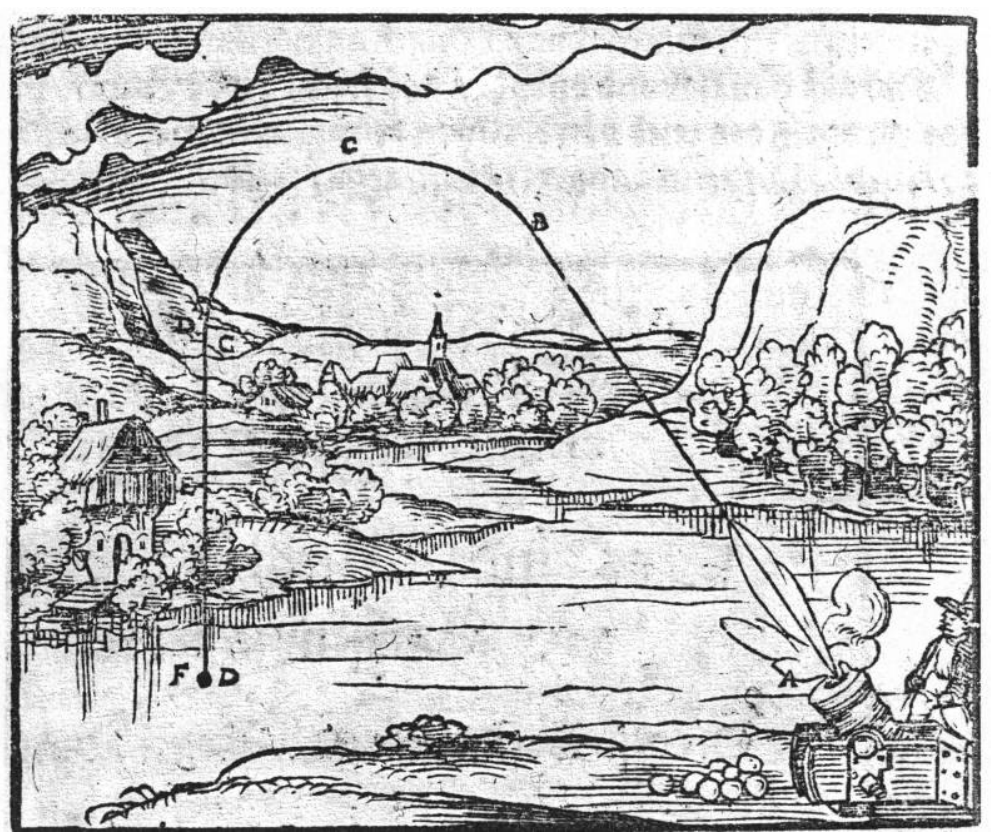

Figura 1 - Trajetória de um projétil de acordo com a Teoria do Impetus

Fonte: Walther Hermann Ryff, Bawkunst, Basel: Henricpetri, 1582. Disponível em:

<http://www.natuurwetenschappen.be/common/pdf/educa/summercourse/Johan_de_Smedt/indexs.html>. Acesso em: 3 maio 2010

Simular balas de canhão que respeitem as Leis de Newton não foi muito difícil porque objetos físicos, tal como explicado acima, são automaticamente afetados pela gravidade e colisões com outros objetos (Second Life Wiki, n.d., Non-Physical). Portanto, simplesmente tornando estas balas de canhão físicas fará com que o physics 
engine Havok se encarregue de simular - de forma razoavelmente acurada - o comportamento físico newtoniano e realizar um caminho aproximadamente parabólico até o chão, como esperado. Ele definitivamente não será acurado, uma vez que, como dito acima, o SL na tem o objetivo de simular a Física Newtoniana; mas, apesar disso, estas balas de canhão simulam uma trajetória parabólica suficientemente bem, como se vê da Figura 3.

Simular balas de canhão que respeitassem a Teoria do Impetus de Buridan, porém, foi um desafio completamente diferente. De acordo com esta teoria, como visto acima, os períodos inicial e final da trajetória do projétil devem ser linhas retas, mas objetos físicos, sendo sujeitos à gravidade, realizam trajetórias parabólicas, tal como discutido antes.

Era, portanto, imperativo contrabalançar a gravidade através de um script especial, inserido nas balas de canhão e que atuaria tão logo elas fossem materializadas. Esta opção também era conveniente, já que não era desejável ter dois scripts diferentes no canhão para as diferentes balas - a diferença deveria residir na própria bala. Foram tentadas duas soluções: 1) incluir uma força para cima com valor igual à da força da gravidade e 2) seguindo a sugestão de Como Moore, Thome, and Haigh (2008, p. 159), definir o valor do empuxo ${ }^{1}$ - a força para cima exercida por um fluido que se opõe ao peso do objeto - como 1,0, em vez do valor padrão 0.0. Entretanto, tanto num caso como no outro, quando o atributo PHYSICAL é ativado num objeto através de um scrpit, ele aciona o physics engine Havok, que leva, no entanto, alguns décimos de segundo para estar ativo, o que permite que a bala, entretanto, caia certa distância em direção ao chão, por força da gravidade ainda não contrabalançada (Figura 2). O restante da trajetória seria razoavelmente linear, mas a queda inicial arruinava a simulação.

\footnotetext{
${ }^{1} \mathrm{Na}$ vida real, o empuxo afeta objetos imersos num fluido - um sólido num líquido, um líquido em outro líquido, etc.-- enquanto que, no SL, um valor de 1,5 para a 'buoyancy' fará com que o objeto flutue da mesma forma, acima de qualquer coisa, sem levar em conta qualquer nível da água. (LSL Wiki, n.d., llSetBuoyancy) O nome "buoyancy" é enganador e consideramos que este recurso poderia ser melhor compreendido como uma 'flutuabilidade' já que buoyancy parece funcionar como uma propriedade do objeto em si.
} 


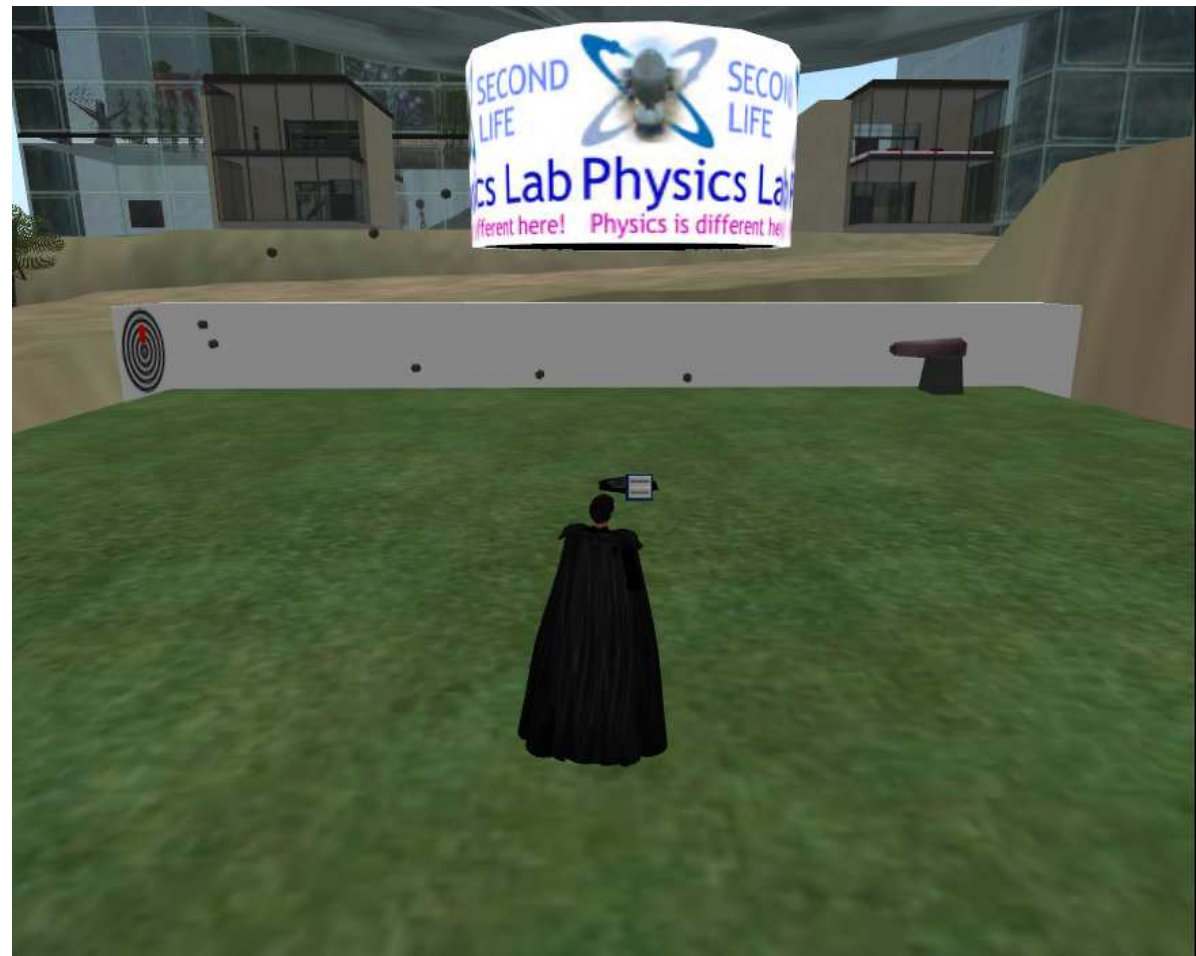

Figura 2 - Projéteis caindo ao chão devido ao atraso do scrpit em contrabalançar a gravidade Fonte: foto tirada pelo autor

Como não se encontrou nenhuma maneira de neutralizar eficazmente a gravidade, a opção de balas buridanianas físicas foi abandonada e tratou-se de torná-las não-físicas, isto é, não sujeitas a interações e forças físicas, desta forma, evitando resistência do ar e efeitos da gravidade. Isto pode ser conseguido ajustando a propriedade STATUS_PHYSICS como FALSE no objeto, antes de incluí-la no inventário do canhão.

No entanto, como visto acima, objetos não-físicos no SL tendem a permanecer estáticos e só se moverão através do uso de scripts cinemáticos (LSL Wiki, n.d., NonPhysical). As balas buridanianas não-físicas se acumulavam na boca do canhão à medida que eram materializadas pela função $l l R e z O b j e c t$ incluída no script do canhão. Precisava-se, portanto, de uma maneira de colocá-las em movimento. A única função cinemática disponível era $l l S e t P o s$, mas ela não move realmente objetos não-físicos, mas apenas altera suas posições. Um observador não vai vê-los movendo-se da posição inicial para a fina (SL Wiki, n.d., llSetPos); o objeto vai, repentinamente, aparecer 'lá'. Isto, obviamente, não iria realizar o movimento sob ação de impetus, como descrito acima.

Após alguma consideração, uma solução baseada nos frames do cinema: dividir a trajetória desejada em tantos intervalos quanto possível e usar um do loop, no script interno da bala de canhão buridaniana, para fazer a função llSetPos mover a bala aos pontos intermediários sucessivamente. Se os deslocamentos e os intervalos de tempo fossem suficientemente curtos, isso poderia realizar um movimento razoavelmente fluido. Esta simulação da Teoria do Impetus de Buridan funcionou razoavelmente, como se vê na Figura 4.

Embora avatares não possam se machucar de verdade no SL, para aumentar a sensação de imersão, o canhão foi colocado dentro de uma 'câmara de segurança' e um painel de controle estilo ficção científica foi incluído. Esse painel tem dois botões: um, 
rotulado 'Newtonian Physics Cannonballs', faz com que os projéteis realizem a trajetória parabólica prevista pela teoria de Galileu/Newton, conforme se vê na Figura 3.

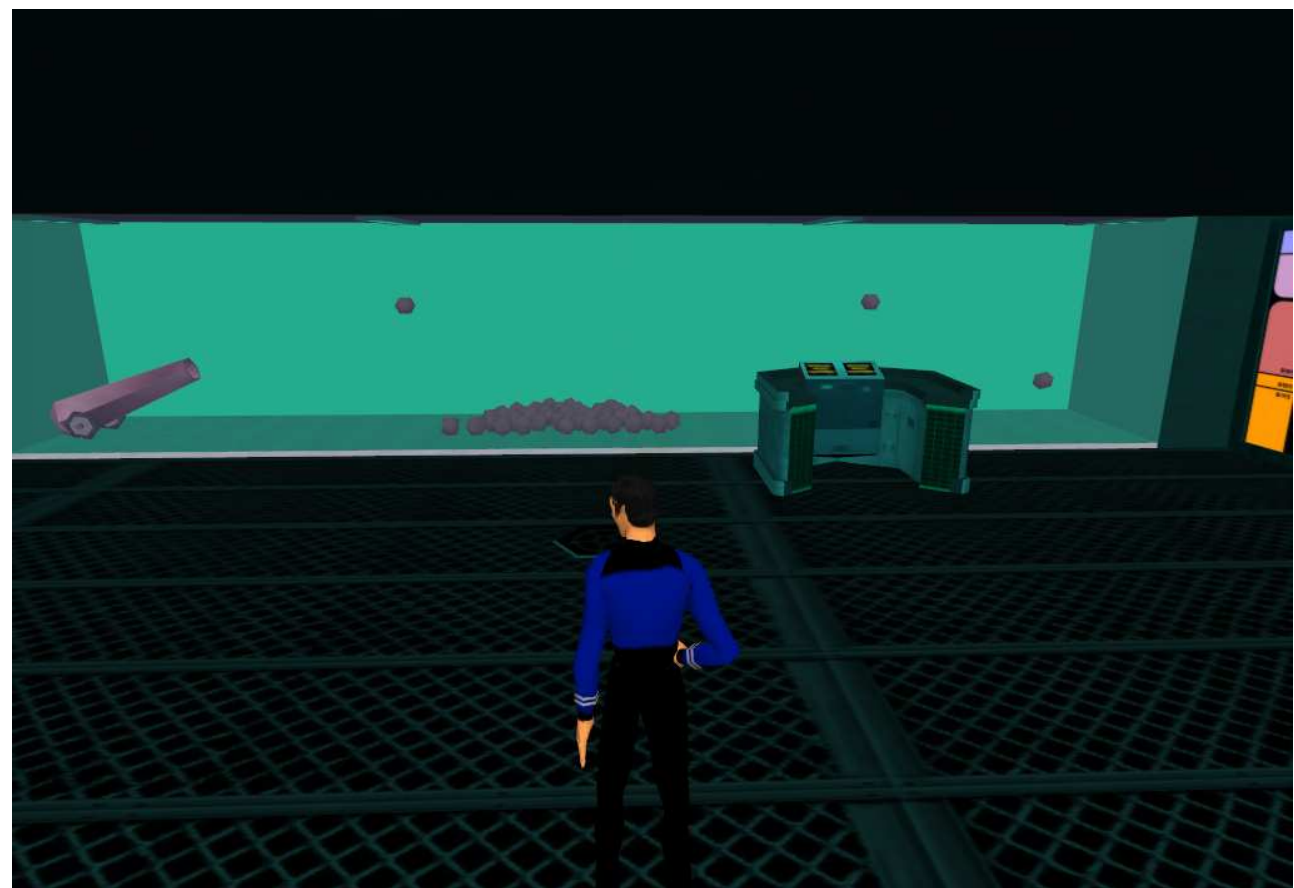

Figura 3 - Projéteis seguindo a usual trajetória parabólica da Mecânica Newtoniana Fonte: foto tirada pelo autor

Se, no entanto, o outro botão, rotulado 'Buridanian Physics Cannonballs', for acionado, serão disparadas balas que seguem a trajetória mostrada na Figure 4, que se aproxima da prevista pela famosa Teoria do Ímpeto (impetus) de Buridan, como ilustrada na Figura 4.

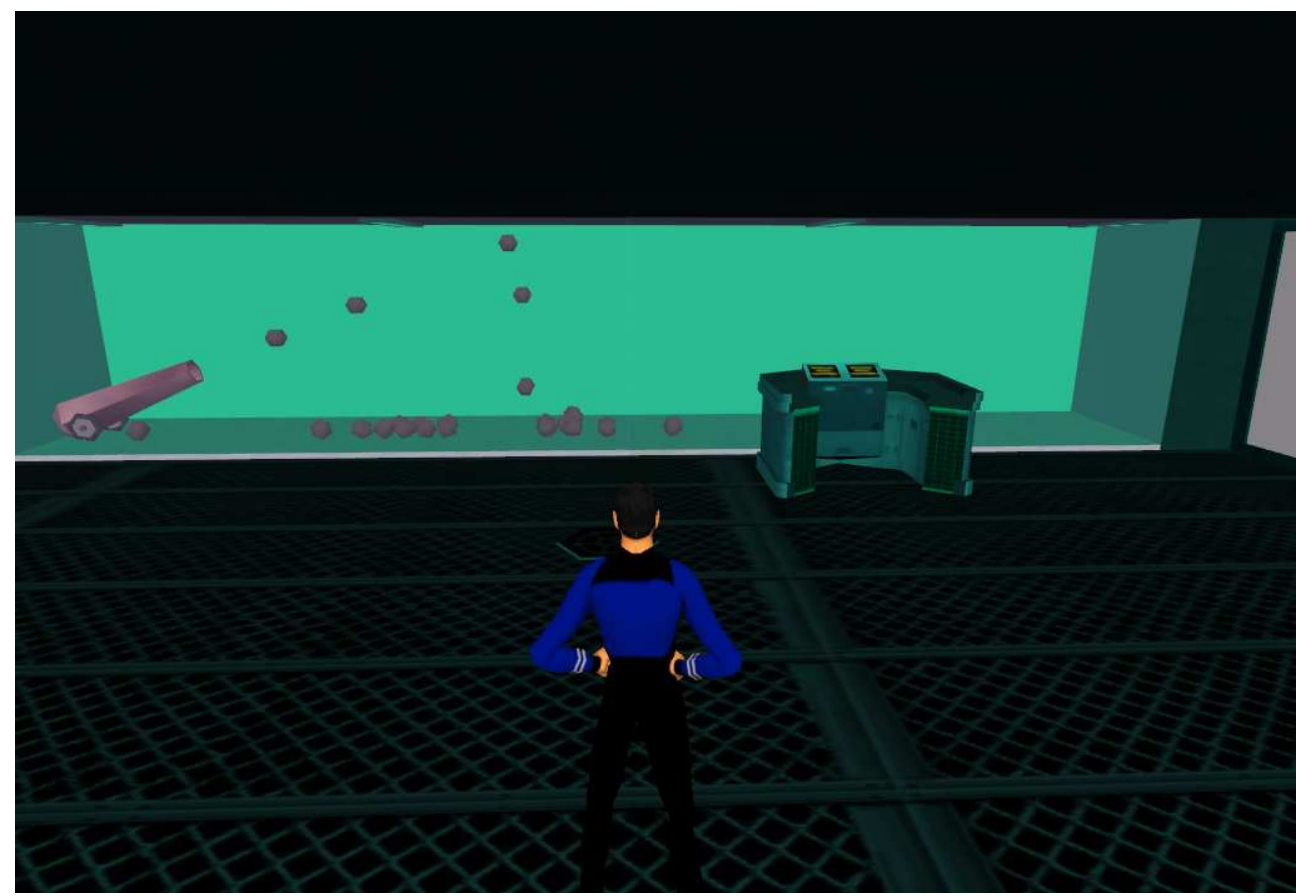

Figura 4 - Projéteis reproduzindo a trajetória prevista pela Teoria do Impetus de Buridan Fonte: foto tirada pelo autor 
O funcionamento deste 'canhão' pode ser visto nos vídeos (Second Life Physics, 2010a, 2010b) ou experimentado no micromundo Second Life Physics Lab, situado nas coordenadas Castelo/55/100/60).

Uma questão que naturalmente surge aqui é sobre a eficácia deste micromundo físico para o aprendizado de Física. Antes de levá-lo a um teste com estudantes reais, todavia, consideramos de suprema importância dispor de instrumentos adequados para avaliar corretamente a eficácia dessa interação num mundo virtual. No momento, tendemos ao referencial epistemológico de primitivas fenomenológicas de diSessa (1993), o qual parece prover o detalhe microscópico das sutis mudanças na cognição do estudante que se podem esperar de algumas poucas explorações dos micromundos. Estamos trabalhando num instrumento apropriado e esperamos dispor em breve de dados a relatar.

\section{Conclusões}

Deste trabalho de simulação de trajetórias retilíneas no SL, pode-se concluir que a realização da idéia de Papert (1985) de permitir que os estudantes manipulassem diretamente os não-intuitivos objetos newtonianos com velocidade constante, seria um desafio ainda maior. Greis (2008) persegue esta ideia para a construção de uma versão 3D imersiva e social do bem conhecido dispositivo de laboratório de Física, usualmente denominado 'trilho de ar' (air track), que pretende demonstrar colisões elásticas, de um ponto de vista estritamente newtoniano. No entanto, como Andrew Linden, co-fundador da Linden Lab e desenvolvedor do SL, comentou uma vez (Linden, 2010), mover um objeto a uma velocidade constante é presentemente muito difícil.

Como mencionado antes, o principal objetivo deste trabalho foi prosseguir a idéia da hiperrealidade da Física do SL e de seu potencial surreal, expressa por Santos (2008, 2009), para demonstrar, através do exemplo de um 'canhão', a viabilidade do ambiente do SL como suporte para micromundos físicos e simulações que, integrando História da Ciência, permitam experimentação pedagogicamente efetiva com sucessivas leis físicas, diferentes das de Newton, num referencial histórico-psicogenético piagetiano, tal como proposto por Papert trinta anos atrás.

Como mostrado, este 'canhão' pode simular a mecânica Newtoniana tanto quanto sua predecessora, a Teoria do Impetus de Buridan, à escolha do usuário. Portanto, se constitui num simulador propriamente dito, em que o usuário, mais do que apenas interagir com ele, pode alterar um parâmetro do sistema e observar a consequência. Acreditamos que o objetivo foi alcançado. A viabilidade do ambiente Second Life como suporte para micromundos e simulações que disponibilizem a experimentação com leis físicas diferentes das newtonianas, tal como proposto por Papert (1985) há trinta anos, foi, portanto, demonstrada. Ainda não é possível, é claro, manipular uma variedade infinita de leis de movimento, como na visão de Papert (1985). Apesar disso, embora muito simples, este 'canhão', tanto quanto se conseguiu verificar, é o primeiro dispositivo que realiza essa proposta.

As opiniões expressas aqui são exclusivamente do autor e não representam a visão ou opiniões de seu empregador ou da agência financiadora.

\section{Referencias}

ABELSON, Harold; diSESSA, Andrea A. Turtle Geometry: Computations as a Medium for Exploring Mathematics. Cambridge : MIT Press, 1981.

BURIDAN, Jean, Quæstiones super Octo Libri Physicorum, Book 8, Question 12, [13--]. 
CROMBIE, Alistair C., Augustine to Galileo: the History of Science a.d. 400-1650, William Heinemann, Ltd., London, 1957.

GREIS, Luciano Kercher; REATEGUI, Eliseo. Um Simulador Educacional para Disciplina de Física em Mundos Virtuais. RENOTE: Revista Novas Tecnologias na Educação, UFRGS, v. 8, n.2, jul. 2010. Disponível em:

<http://seer.ufrgs.br/renote/article/viewFile/15220/8984>. Acesso em: 24 ago. 2010.

LINDEN, Andrew [Andrew Meadows]. (2010). Second Life Wiki - Andrew

Linden/Office Hours, August 24, 2010. Disponível em:

<http://wiki.secondlife.com/wiki/User:Andrew_Linden/Office_Hours/2010_08_24>. Acesso em: 27 abr. 2010.

LOPES, Cristina Videira. The massification and webification of systems' modeling and simulation with virtual worlds. In: ESEC/FSE '09 (Proceedings of the the 7th joint meeting of the European software engineering conference and the ACM SIGSOFT symposium on The foundations of software engineering, Amsterdam). pp. 63-70. New York: ACM, 2009.

LSL Portal. s.d. Disponível em: <http://wiki.secondlife.com/wiki/LSL_Portal>.Acesso em: 29 out. 2008.

LSL WIKI. s.d. Disponível em: 〈http://lslwiki.net/lslwiki/>. Acesso em: 29 out. 2008.

MASSON, Steve; LEGENDRE, MARIE-FRANÇOISE. Effects of Using Historical Microworlds on Conceptual Change: A P-prim Analysis. International Journal of Environmental \& Science Education, v. 3, n. 3, pp. 115-130, Jul. 2008.

MASSON, Steve; VÁZQUEZ-ABAD, Jesús. Integrating History of Science in Science Education through Historical Microworlds to Promote Conceptual Change. Journal of Science Education and Technology, v. 15, n. 3-4, pp. 257-268, Oct. 2006.

MEDEIROS, João. Doing physics in Second Life, Physics World, v. 21, pp. 12-13, 1 fev. 2008.

MIKROPOULOS, TASSOS A.; NATSIS, ANTONIS. Educational virtual environments: A ten-year review of empirical research (1999-2009). Computers \& Education, v. 56, n. 3, pp. 769-780, Apr. 2011.

MOORE, Dana; THOME, Michael; KAREN, Haigh. Scripting Your World: The Official Guide to Second Life Scripting. Berkeley, CA: Sybex, 2008.

MOREIRA, Marco Antonio \& GRECA, Ileana Maria. Cambio Conceptual: Análisis Crítico y Propuestas a La Luz de la Teoría del Aprendizaje Significativo. Revista Ciências e Educação. Ciência e Educação, v. 9, n. 2, p. 301-315, 2003.

MORTIMER, Eduardo Fleury. Conceptual change or conceptual profile change?

Science \& Education, v. 4, n. 3, p. 265-287, 1995.

PAPERT, Seymour. Micromundos: incubadores para o conhecimento. In: Logo:

Computadores e Educação. São Paulo: Editora Brasiliense, 1985, pp. 148-164.

PIAGET, Jean; GARCIA, Rolando, Psicogénese e História das Ciências, Lisboa: Dom Quixote, 1987.

SANTOS, Renato P. dos. Virtual, Real ou Surreal? A Física do Second Life. RENOTE: Revista Novas Tecnologias na Educação, UFRGS, v. 6, n. 2, dez. 2008. Disponível em: <http://www.cinted.ufrgs.br/renote/dez2008/artigos/1b_renato.pdf>. Acesso em: 31 ago. 2008. 
Second Life Physics: Virtual, Real or Surreal? Journal of Virtual Worlds Research, v. 2, n. 1, (special issue: Pedagogy, Education and Innovation in Virtual Worlds), Apr. 2009. Disponível em <https://journals.tdl.org/jvwr/article/view/383/455>. Acesso em: 31 ago. 2008.

SECOND LIFE Physics - Cannon simulation Part 1: Buridanian Impulse Theory. Porto Alegre, 2010. Disponível em: <http://www.youtube.com/v/OM7ToMjDdWI>. Acesso: 8 jun. 2010.

SECOND LIFE PHYSICS - Cannon simulation Part 2: Newtonian Law. Porto Alegre, 2010. Disponível em: <http://www.youtube.com/v/reneVbLYDA0>. Acesso: 8 jun. 2010.

SECOND LIFE WIKI. s.d. Disponível em:

<http://wiki.secondlife.com/wiki/LSL_Portal>. Acesso em: 29 out. 2008.

SECOND LIFE WIKIA. s.d. Disponível em: <http://secondlife.wikia.com/>. Acesso em: 29 out. 2008.

TEODORO, Vitor Duarte; VIEIRA, João Paulo Duque; CLÉRIGO, Filipe Costa.

Modellus, Interactive Modelling with Mathematics. Disponível em:

<http://modellus.fct.unl.pt/course/view.php?id=16\#2> Acesso em: 29 out. 2008.

VRELLIS, Ioannis Vrellis; PAPACHRISTOS, Nikiforos M.; NATSIS, Antonis Natsis ; MIKROPOULOS, Tassos A. Measuring presence in a collaborative physics learning activity in Second Life. In: JIMOYIANNIS, Athanassios (ed.), Proceedings of the 7th Pan-Hellenic Conference with International Participation «ICT in Education», University of Peloponnese, Korinthos, Greece, 23-26 September 2010, v. 1, pp. 95-102, 2010. 